San Jose State University

SJSU ScholarWorks

Faculty Publications, School of Management

School of Management

$1-1-2008$

\title{
The Impact of a Marketing Information System: A Case Study of SMART-Baltimore
}

Tanvi Kothari

San Jose State University, kothari.t@gmail.com

D. R. Fesenmaier

\section{Z. Xiang}

Follow this and additional works at: https://scholarworks.sjsu.edu/org_mgmt_pub

Part of the Business Administration, Management, and Operations Commons, and the Strategic Management Policy Commons

\section{Recommended Citation}

Tanvi Kothari, D. R. Fesenmaier, and Z. Xiang. "The Impact of a Marketing Information System: A Case Study of SMART-Baltimore" Information Technology and Tourism (2008): 59-74. https://doi.org/10.3727/ 109830508785059020

This Article is brought to you for free and open access by the School of Management at SJSU ScholarWorks. It has been accepted for inclusion in Faculty Publications, School of Management by an authorized administrator of SJSU ScholarWorks. For more information, please contact scholarworks@sjsu.edu. 


\title{
THE IMPACT OF A MARKETING INFORMATION SYSTEM: A CASE STUDY OF SMART-BALTIMORE
}

\author{
TANVI KOTHARI*, ZHENG XIANG $\dagger$, and DANIEL R. FESENMAIER $\dagger$ \\ *Department of General and Strategic Management, Temple University, Philadelphia, PA, USA \\ $\lceil$ School of Merchandising and Hospitality Management, University of North Texas, Denton, TX, USA
}

\begin{abstract}
The purpose of this study is to use existing theories of technology and organizational change to assess the impact of technology implementation within the context of the tourism industry. The framework is applied as a case study to analyze the perceived implications of implementing a destination marketing information system by the Baltimore Area Convention and Visitors Bureau. The results of the study indicate that the most important value of the system is the richness and timeliness of information. The key informants perceive that this system will not only impact the marketing activities at the organization but will not influence the overall organizational activities. Finally, this article discusses the importance of these findings for destination marketing.
\end{abstract}

Key words: Destination marketing organizations; Marketing information systems; Technology impact; Technology evaluation; Organization change

\section{Introduction}

Convention and Visitor Bureaus (CVBs) serve the role of an information broker for the tourism industry by facilitating the flow of information between industry players (Yuan, Gretzel, \& Fesenmaier, 2003, p. 1). Bureaus provide information to tourists, exchange information with its members and other CVBs and collect information from tourists and other segments (Poon, 1993; Schertler, 1994). Because information is of central strategic importance to the tourism industry, the ability of CVBs to leverage information largely determines its competitive advantage (Buhalis, 1998; Poon,
1993; Porter, 1985; Wöber 2003; Yuan \& Fesenmaier, 2000). Therefore, to remain competitive in an increasingly sophisticated marketplace, bureaus must invest in information technology (IT). The importance of information and efficient information management at organizations is steadily increasing not only due to the evolution of new technologies and high-capacity storage media, but also because of growing competition that raises information needs. Advances in IT have enabled destination marketing organizations to enhance their competitive advantage while simultaneously enabling competitors to enter existing markets more readily. Thus, it is argued that only those organiza- 
tions that are able to respond quickly to the demands of the new tourism economy will be the winners of the 21 st century (Werthner \& Klein, 1999).

Despite substantial investments in IT, the impact of IT on productivity and business performance continues to be questioned (Willcocks \& Lester, 1997). Is IT worth the investment? Can the value of investing in a particular system be measured? And what are the impacts of adopting a particular system on the bureau itself and its stakeholders? These questions are being asked more and more as tourism organizations invest in technology and fail to see the real impact in terms of productivity. The difference between investment and expectation creates what is called the IT Productivity Paradox (Brynjolfsson, 1993) or the Information Paradox (Thorp, 1996). It is the mismatch between the amount of money an organization spends on IT and actual improvements in information delivery and business value. Studies suggest that investment in IT does not necessarily bring about improvements in organizational operation (Gates, 1999; Templer, 1989).

As the workplace becomes more and more technology based, an important question is how to assess the impact of IT. The lack of good quantitative measures for the output and value created by IT makes the MIS manager's job of justifying investments particularly difficult. Barua, Kriebel, and Mukhopadhyay (1991) studied IT's effect on intermediate variables such as capacity utilization, inventory turnover, quality, relative price, and new product introduction and found that IT was positively related to three of these five intermediate measures of performance, although the magnitude of the effect was generally too small to measurably affect return on assets or market share. Various researchers have indicated the potential benefits from adopting a process-oriented view to assessing the value of information technology (Banker, Kauffman, \& Morey, 1990; Kauffman \& Weill, 1988; Wilson, 1993). However, organizational decisions, processes, and practices that lead to this information/productivity paradox are still not well understood in the filed of tourism. Implementing efficient information systems in convention and visitor bureaus is especially challenging due to the nature of the tourism product (intangi- bility, perishability, heterogeneity, and a multitude of components), the complexity of the industry structure (dominated by small, highly interdependent but geographically dispersed organizations) (Poon, 1993), and the lack of capacity of destination organizations to conduct market research (Wöber 2003). Very few studies have directly examined how and why IT is actually used and managed within the context of convention and visitor bureaus (Gretzel \& Fesenmaier 2001; Wöber \& Gretzel, 2000; Yuan et al., 2003). The purpose of this study is to integrate existing theories of technology and organizational change in order to build a framework that describes the impact of technology implementation within the context of the tourism industry. The proposed framework is then applied as a case study to understand the implications of adopting and implementing a market information system at Baltimore Area Convention and Visitors Bureau (BACVA), a leading tourism organization in the US.

\section{A Framework for Technology Adoption and Organizational Change}

IT evaluation is a process that attempts to assess the contribution of an information systems investment. Farbey, Land, and Target (1999) define IT evaluation as "a process, or group of parallel processes, which take place at different points in time or continuously, for searching and for making explicit, quantitatively or qualitatively, all the impacts of an IT project and the programme and strategy of which it is a part" (p. 190). In terms of timing of the evaluation, it is suggested that there are two key points at which the contribution is evaluated. Initially, "ex-ante" evaluation is conducted prior to the systems development in order to justify the investment; then, "ex-post" evaluation is undertaken following implementation to confirm the value of the system (Remenyi, Sherwood-Smith, \& White, 1998). The starting point for this study is the assumption that prior to making a decision to adopt a particular IT the bureau evaluates the pros and cons of the technology. Based on this initial evaluation, the decision is made to adopt or not to adopt the technology (i.e., a destination marketing information system) at the organization. 
Much of the technology diffusion literature focuses on the adoption decisions of individuals, either for themselves or for their employers. But for organizations, many technologies are "too big and complex to be grasped by a single person's cognitive power-or usually, to be acquired or deployed within the discretionary authority of any single organizational participant" (Tornatzky \& Fleischer, 1990, p. 133). Thus, a more robust framework is needed to study organizational adoption. An influential framework for understanding MIS adoption in an organizational context has been developed by DePietro, Wiarda, and Fleischer (1990). Their model defines a "context for change" consisting of three elements:

- Technology: The model integrates the five innovation attributes that Rogers (1983) showed influence the likelihood of adoptions. The authors also note that radical innovations increase the relative advantage but reduce the compatibility of the innovation.

- Organization: Adoption propensity is influenced by formal and informal intraorganizational mechanisms for communication and control. The resources and innovativeness of the organization also play an obvious role.

- Environment: Consistent with Porter (1985), a firm's strategic IS decisions will depend in part on industry characteristics such as rivalry, relations with buyers and suppliers, as well as the stages of the industry life cycle (DePietro et al., 1990, pp. 169-171).

These three elements (referred to as "TOE") are posited to interact with each other and to influence technological innovation decision making (DePietro et al., 1990, p. 153). In fact, the TOE framework as originally presented, and later adapted in IT adoption studies, is a useful analytical tool for distinguishing between inherent qualities of an innovation itself and the motivations, capabilities, and broader environmental context of adopting organizations. This study proposes that once the decision is made in favor of adoption of the technology, one can begin to assess the nature and extent of organizational change based on the framework shown in Figure 1. Following Dewey (1929) and DePietro et al. (1990), it is posited that organizational change results from the interaction between these components (technology, organization, and environment) and the CVB's marketing practices and culture. The following provides a brief description of each component as it relates to organizational change.

\section{Technology}

While contingency theorists (Van de Ven \& Drazin, 1985) argue that an organization's structure must "fit" its organizational context, the technology must also fit organizational goals. The construct Technology can be defined using three sets of variables: 1) level of integration of technology in the organization; 2) the type of project for which technology is being adopted; and 3) fit between the task and technology. For instance, the level of integration of the technology adopted and implemented in an organization could vary from simple individual-oriented information technologies to more complex and sophisticated organizational technologies that are the focus of managerial concern and, thus, would cause different impacts on the organization and its environment. Technology also includes variables that differentiate two different types of projects for which the technology is being adopted. The distinction between efficiency and effectiveness has been made in a number of studies [e.g., Hill (1993)], wherein efficiency is broadly concerned with how we do things and effectiveness is concerned with what we do. Efficiency projects are defined as ones that seek to reduce the cost of performing a particular process or task by utilizing information technology. Effectiveness projects aim not just to reduce the costs of performing existing tasks but also to identify ways of doing different things that better achieve the required results, leading to increased revenues, better service, etc. The benefits realization process for an effectiveness project comprises at least two stages (Fitzgerald, 1998): first, the provision or implementation of the project to provide benefit and, secondly, the effect of that benefit on the wider environment and any resultant behavior change. Due to this two-stage benefits realization process, effectiveness projects are typically of higher risk than efficiency projects.

The task-technology fit model (Goodhue, 1995) can also be used to describe the relationship 


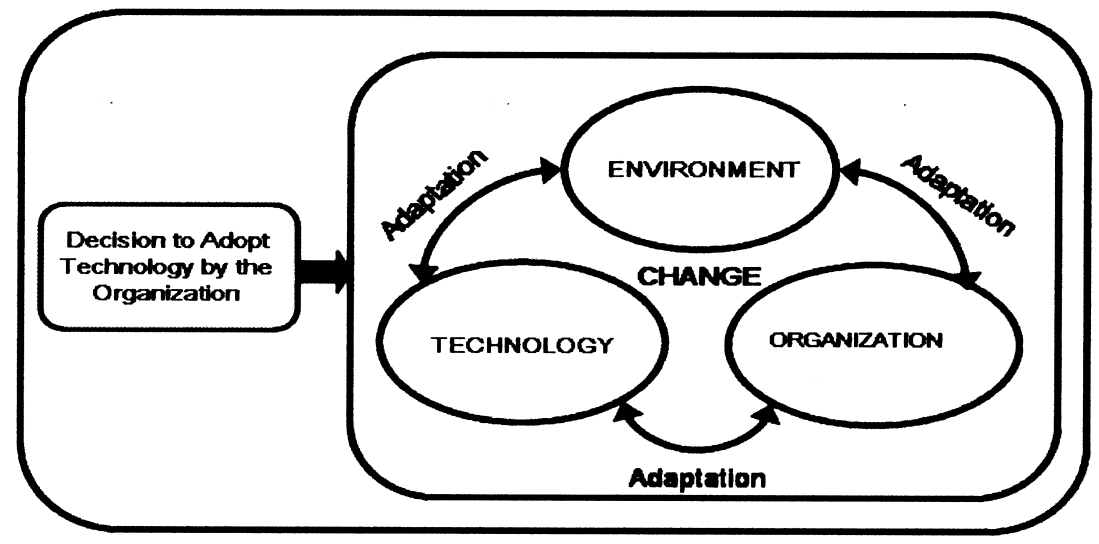

Figure 1. A framework for technology adoption and organizational change.

between technology and task, a major aspect of organizational structures. Recent advances in IT have significantly enhanced a system's capability to not only support task specific decision making, but also to facilitate learning through information with a variety of decision support through realtime access to market data, experimentation with variables, simulation, trend analysis, exploration and exploitation of knowledge, and idea generation (Bhatt \& Zaveri, 2002). The development of IT and the rebirth of direct marketing also enable and necessitate a more interactive dialogue and direct interface between producers and customers (Palmer, 1996; Seth \& Parvatiyar, 1995).

In the last few years, a number of tourism information systems have been developed in order to provide the industry, especially destination organizations, with the means to collect and manage data, interpret information, share knowledge, and support decision making (Fesenmaier, Leppers, \& O'Leary, 1999; Mazanec, 1986; Ritchie \& Ritchie, 2002; Wöber 2003; Wöber \& Gretzel, 2000). A marketing information system is crucial to an organization as it supports the organization in collecting, storing, processing, and disseminating information, and in the decision-making process by providing forecasts and decision models (Little, 1970; Wöber 2003). The adoption and implementation of such systems could be considered as an effectiveness project and needs to be evaluated. Thus, this construct incorporates variables such as "task," which includes various purposes (knowl- edge, information, and communication tools) for which technology is being used.

\section{Organization}

Drucker (1985) defined the organization as, "a structure in which information serves as the axis and as the central structural support." The construct Organization includes two sets of variables. The first set is described as structural variables, which define the ways in which an organization divides its tasks and then coordinates them. Organization structure defines the formal relationships among people and specifies both their roles and their responsibilities. Both formal and informal structures exist within an organization that serve to process and move data (Bateman \& Zeithaml, 1993). Formal structures are those that are explicitly detailed in an organization chart and formal procedures. They include formal communication channels and systems that are designated by management to collect and discriminate information. Informal structures refer to those social relationships that emerge from the interaction of individuals within the organization (Tushman \& Scanlan, 1981). Leadership roles and information flows in the informal structure are not defined in the formal organization; however, employees look to these channels or individuals as an important source of information (Daft \& Lengel 1986). Studies suggest that the successful development of destination marketing systems could be associated with its or- 
ganization structure (Mutch, 1996) in that internal structures need to link loosely coupled unites and assist staff to work as a team in a networked environment (Werthner \& Klein, 1999). Thus, success depends upon good working cooperation from all sides (Elliott, 1997).

The second set of organization related variables are process variables, which facilitate the implementation and adoption of a technology at a particular organization. Davenport and Short (1990) present a three-dimensional classification structure relating to the organizational entities involved in the processes, the types of objects manipulated, and the type of activities taking place. They include interorganizational processes, interfunctional processes, and interpersonal processes. Interorganizational processes are those taking place between two or more business organizations. Increasingly, organizations are concerned with coordinating activities that extend into the next (or previous) organization along the value added chain. Interfunctional processes exist within the organization, but cross several functional boundaries. In order to produce quality products and services it is necessary to address difficult interfunctional issues. Interpersonal processes involve tasks within and across small work groups, typically within a function or department. This type of process is becoming more important as organizations shift to self managing teams whereby each element must support each of the others and together they must support the organization's purpose.

\section{Environment}

It is posited that Dewey's philosophy of "instrumentalism" (1929), which suggests that human beings are not "subjects" or "isolated individuals" but are originally and continually tied to their environment, provides the essential foundation for understanding the role of environment. Duncan (1972) defines an organization's environment as, "the totality of physical and social factors that are taken directly into consideration in the decision making behavior of individuals in the organization" (p. 314). Scott (1961), in his discussion on organization theory, emphasizes that the only meaningful way to study the organization is to study it as a system and that the distinctive feature of modern organization theory was in its conceptualization of an organization as an open system. Terreberry (1968) provides evidence that contemporary organizations are experiencing decreasing autonomy and increasing interdependence. She posits that: a) organizational environments are increasingly turbulent; b) organizations are increasingly less autonomous; and c) formal organizations are increasingly important components of organizational environments. Furthermore, tourism is place oriented, and the areas surrounding a tourist attraction are important; hence, successful, high-quality tourism involves not just individual businesses but the environment and the community surrounding tourism businesses (Murphy, 1985). Management and marketing of tourism often require a community effort because of the nature of tourism: the community as a whole and its image must be marketed, not just one attraction. From an information perspective, every change or development in the external environment creates signals and messages that an organization may need to heed (Dill, 1962). Some of the signals would be weak (difficult to detect), many would be confusing (difficult to analyze), and others would be spurious (not indicative of a true change). Sutton (1988) suggests that organizations scan their environment in order to avoid surprises, identify threats and opportunities, gain competitive advantage, and improve long-term and short-term planning.

The proliferation of IT creates opportunities and threats in the tourism industry that are pushing and pulling IT implementation. On one hand, the value of external opportunity created by IT encourages the adoption and implementation of IT (Yuan, Gretzel, \& Fesenmaier, 2006). Opportunities are created due to changes in the behavior of consumers, alternative service/product delivery channels, and changes in business operations (Fesenmaier et al., 2004). On the other hand, the widespread use of IT has changed the rules that govern the industry as well as the composition of the industry (Poon, 1993; Werthner \& Klein, 1999). These changes have resulted in a substantial expansion in the availability and transparency of information, new forms of competition, and an increase in the speed with which changes occur (Gates, 1999; Kanter, 2001). Specifically, the construct Environ- 
ment includes the set of external environmental forces (i.e., economic, sociocultural, technological, ecological, and political) that are external to the organization and yet have a significant impact on the organization. War, terrorism, political upheaval, the spread of infectious diseases, airline industry restructuring, and the advancement and use of technology are just a few of the events that are having a profound impact on destinations' performance around the world. However, technology has proven to be one of the greatest agents for change in destination marketing (Fesenmaier et al., 2004; Poon, 1993).

\section{Organizational Change}

In seeking information the organization must attend selectively to a flood of signals created by a dynamic environment, interpret often confusing messages, and make sense of cues in relation to firm's goals and activities. DeSanctis and Poole (1994) posit that both organizations and technologies have structural properties. The structural properties of the technology are modified as it is appropriated to fit organizational needs and constraints. At the same time, some of the organizational structures are changed as a result of the implementation of the technology (Orlikowski, 1992). It has been suggested that this dynamic relationship between organization and technology results in observable implementation effects over time and encourages development that leads organizations through three distinct evolutionary stages: Substitution, Enlargement, and Reconfiguration (Contractor, Stohl, Monge, Flanagin, \& Fulk 2000). Figure 2 shows that technology adoption and diffusion typically occurs in three stages and that higher levels of technology use require increasing knowledge that needs to be carefully and actively managed (Contractor, Wasserman, \& Faust 1999; Gretzel \& Fesenmaier 2001). The early adoption of the emerging digital technologies reflects an attempt to use them as "substitutes" for existing modes (technological and nontechnological) and is heralded as offering faster, cheaper, and more accurate channels to support existing organizational structures and practices. At a second stage of adoption, the economies provided by these digital technologies are used to justify the "enlargement" of the activi-

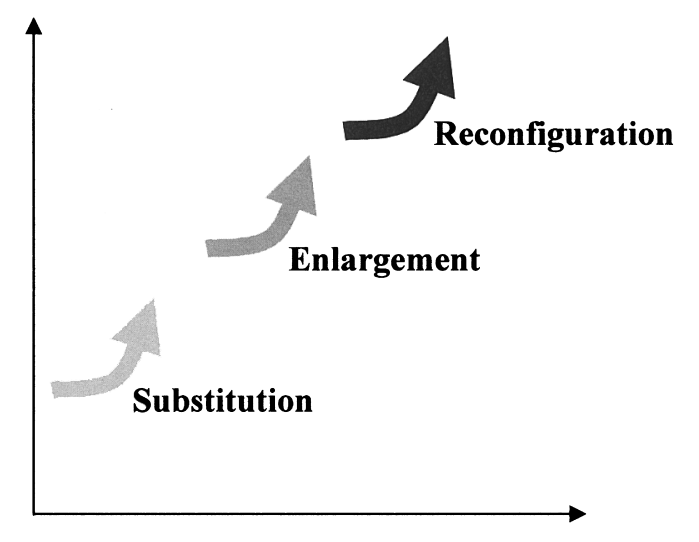

Figure 2. Stages of technology adoption and diffusion (adapted from Contractor et al., 1999).

ties. It is characterized by enlargement in every aspect of the use of technology by which organizations can capture some of the benefits of technologies and expand their services. Research suggests that the more enduring consequences of an emerging technology coincide with a third "reconfiguration" stage of adoption. It is considered to be the "ideal stage" as it implies that organizations proactively learn and continuously adapt to changing technologies and markets, thus ensuring long-term competitive advantages. In this stage, technologies are used to fundamentally reconfigure organizational structures and practices.

Thus, it is argued that organizations differ in the way they adopt and use technology. That is, adaptation to technological change cannot be realized without changes in the organizational structure and culture. Indeed, it appears that the most important reason why the implementation of technologies fails is that organizations fail to initiate necessary changes. A recent study by Yuan et al. (2006) shows that most American CVBs apply IT to facilitate some of their tasks in order to expand their market reach but do not use IT as a means to refine their position within the tourism market.

The framework outlined in Figure 1 suggests that interactions between the organization, environment and technology during the implementation of new technology impact a CVB's working practices and culture. Changes in the organization can be labeled as impact variables, which describe the impact of adopting and implementing technol- 
ogies within the organization. They can further be classified as Planned Impacts and Incidental Impacts. Planned Impacts refers to impacts that are clear and critical outcomes of implementing a particular technology and are an integral part of the system design from the start. For example, impacts may be measured through the following question: How will the system contribute to an organization's efficiency, effectiveness, and competitive positioning? Incidental Impacts are the byproducts of technology implementation (Dohertya, Kinga, \& Al-Mushayt, 2003). For example, IT implementation may alter the organization's power distribution, structure, or working practices in ways that had not, or could not have, been envisaged at the outset. It should be noted that the concept of incidental impacts is similar to Fitzgerald's (1998) second-order effects. These often appear as surprises when they occur (Willcocks \& Lester, 1994). Any project that impacts roles, relationships, sources of power, or organizational structures is likely to have second-order effects. These effects, if predicted, can be addressed and, if necessary, mitigated, to be turned into an advantage, or exploited further. If an undesirable impact is detected, it is important that some action is taken to negate the impact. Conversely, if a desirable impact is detected, action might be taken to further exploit it.

The ability to be able to evaluate IT investments effectively is probably of greater importance today than at any time in the past due to: a) the large amounts being spent on IT by organizations; b) the increasing focus on value for money in all areas of business activities; and, c) the developing character of information technology. The increased complexity of information systems combined with the uncertainty and unpredictability associated with information systems benefits and costs clearly point to the need for evaluation procedures not only during preinvestment appraisal and postimplementation review of IT projects but also to continue throughout the life cycle of the system. A benefits management approach implies that the measures of success should be developed preproject so that these measures can be used for postproject review. IT evaluation must also be conducted to ensure that the whole process is still appropriate to meet the business needs and that benefits have been obtained (Sriram, Stump, \& Banerjee, 1997).

\section{A Case Study of SMART-Baltimore}

Following the seminal work of Yin (2002), every case study should start with a general analytic strategy in order to develop a systematic way to find out what is worth analyzing and how it should be analyzed. The ultimate goal is to treat the evidence fairly, to produce compelling analytic conclusions, and to rule out alternative interpretations. The proposed framework was applied to analyze the impact of adoption and implementation of a market information system referred to as SMART (Strategic Market Area Research Technology), which is used by Baltimore Area Convention and Visitors Association (BACVA). A case study methodology appears to provide the best opportunity to learn about situations in which events are currently unfolding (Patton, 1990; Yin, 1984). As suggested by Yin (1984), the research questions must be analyzed in a contemporary real-life context under conditions where there is no control over events and where the boundaries between phenomena and context are not clear cut. The research method for this study adopts a qualitative case study approach that combines inductive and deductive thinking, where theory is a means for understanding the observed rather than the observed is the means for creating or testing theory. The interviews allow for alternative explanations to arise and sustain the inductive character of the work while still maintaining questions within a more or less narrow area of interest. The case study approach also enables the researchers to include other evidence to enhance our understanding of the environment in which this organization exists.

The most important source of case study information is the interview with key informants in that it provides both in-depth qualitative and quantitative information about the decision-making process (Yin, 1984). Studies relating to information technology valuation have suggested that perceptual (subjective) data from senior managers can be employed as acceptable measures of a firm's economic performance (objective measures) (Venkatraman, 1989; Venkatraman \& Ramanujam, 1987). Interviewees who have special knowledge on a 
given topic are characterized as key informants (Mikkelsen 1995). In this study, extensive interviews were conducted with the Chief Operating Office (COO), the Vice President of Marketing, and the Research Manager at the focal organization. They are the key decision makers in the process of adoption and primary users of the market information system. The interviews were constructed as "semistructured interviews" whereby an openended questionnaire (Table 1) was created with items validated in prior research, adapted to the technologies and organizations studied in order to guide the interview process. This interview guide contained an outline of the topics to be covered with suggested questions, many questions were formulated during the interview, irrelevant questions were dropped, and questions were asked according to a flexible checklist and not to a formal questionnaire (Kvale, 1996; Mikkelsen, 1995). Along with the interviews with the key infor- mants, observations of the current practices of the bureau and a review of the documentation data like the bureau's business plan, financial statements, and legal contracts served as important triangulation and supplementary sources for understanding events and the phenomenon, and as a means of gaining additional perspectives on key issues (Miles \& Huberman, 1994). This triangulation approach provided substantial insight into the process and problems of adopting SMART at the bureau.

\section{Baltimore Area Convention and Visitors Association (BACVA)}

The context of this study is the BACVA, which serves the role of an information broker for the tourism industry of Baltimore by facilitating the flow of information between industry players. The BACVA office is located across the Baltimore In-

Table 1

Outline of Semistructured Interview Questions

Question Wording

1. In your opinion, what was the most important reason for BACVA to invest in this market information system?

2. Do you expect this system will assist you in performing your current job function better? If yes, how?

3. Do you perceive that using this system will change ways for doing business? One year from now, what are the changes do you expect to happen?

- Do you foresee that this system will affect the marketing efforts of the organization?

- Do you foresee that this system will help the organization plan for its marketing needs?

- Do you foresee that this system will change the strategic outlook and skill profile of the marketing department?

- Do you think this system will help create or try out new innovative ideas?

4. Do you think this system will exploit unique resources (unavailable to competitors) possessed only by your organization?

5. Would it help to reduce the cost in any functional areas? Do you see this as an ongoing process? Do you think that this system will help you eliminate any non-value added activities existing in your process?

6. Would this system add any distinct value to the organizations competitive advantage?

7. Do you see any organizational risk in integrating this system with the company strategy (i.e., it may not be possible to handle the system with existing management and technical teams)?

8 Do you see any effects of this system on different levels of management and cross-functional areas? Do you think this system will help improve management control and assist the management to control the performance?

9. Do you think introducing this system will affect the attitude of the members of the organization towards the use of technology? How challenging do you think it is to incorporate the system in your organizational culture?

10. How do you think this system is going to change the interaction of the organization with its stakeholders (customers, industry players, with other trade partners)? Would this system add any value to the organizations competitive advantage?

11. What costs did/will the bureau incur in the process of adoption and implementation of this technology/system? Do you seek Return on Investment (ROI) on this system as a tactical/short-term goal or a strategic/long-term goal?

12. How challenging do you think it is to incorporate the system in your organizational culture?

13. Bureau characteristics (organization capabilities/external environment) including background of bureau director. 
ner Harbor, a major tourist attraction in the destination, housing almost 50 employees and is governed by 21 members in its Board of Directors. BACVA is a quasi-public agency operating with limited budgets and funds. BACVA's mission statement indicates that it is the official destination marketing leader for Greater Baltimore Area, responsible for generating incremental economic benefits to the community through the attraction of convention and leisure visits. In its role as the marketing arm for the city of Baltimore, BACVA promotes major businesses, restaurants, meeting facilities, accommodations, and attractions to incoming visitors and conventioneers. Its membership includes major destinations, cultural institutions, and historic sites that are key players in marketing the cultural, entertainment, and historic components of Baltimore. BACVA leaders claim that its partnership between government and private industry has served as a blueprint for other cities. As the region's official destination development and marketing leader, BACVA provides the following services to its members, partners, visitors, community, etc.

- Convention Sales and Services: linking member businesses with incoming convention needs, and dollars;

- Tourism: promoting services through yearround marketing campaigns and initiatives;

- Communications: attracting press coverage of local activities and hot spots;

- Visitor Services: connecting member businesses at street level with tourists, conventioneers, and local residents;

- Membership Support: building members marketing clout through training, insider updates, and other perks;

- Research: BACVA facilitates tourism promotion and marketing research for the Baltimore tourism business.

BACVA appears to have a more flat organizational structure and the nature of communication flows is relatively informal within departments and formal across departments. The decision-making process at the organization is a combination of both centralized and decentralized decisions; however, in case of strategic decisions like the adoption of a new technology that involve costs, the final decisions are made by the top level managers such as the Chief Operating Officer (COO), after considering inputs from other employees. BACVA as an organization seems to have a fairly good historical understanding of their markets as they claim to invest substantially in market research.

\section{SMART-Baltimore}

Following from Fesenmaier et al. (1999), Gretzel and Fesenmaier (2004), and Wöber (2003), the SMART-Baltimore system was developed to assist BACVA in dealing with increasing information needs by providing them with historical, present, and future marketing research data relevant for strategic corporate decisions. The major aim of SMART-Baltimore is to provide a near real-time decision support for BACVA and its members by providing online access to analyze and interpret market data. As such, this system will enable the bureau to establish a series of market performance criteria with which to evaluate the value of markets and other aspects of their organizations. The organizational structure of the system is illustrated in Figure 3; as can be seen, SMART-Baltimore enables users to flexibly queries and segments the dataset as well as allows users to generate data reports for further processing (spreadsheets). This technology also provides the ability for users to benchmark their performances over time.

The primary data for SMART-Baltimore is obtained from visitors collected through an interactive touch screen and implemented as a structured questionnaire. The touch screen systems have been placed at the Visitor Center on the Baltimore Inner Harbor where the visitors stop to obtain information about the destination. As an incentive to participate in the survey, visitors are offered an opportunity to be included in a drawing to win a prize if they provide complete responses to the questionnaire. The data collected through this onsite touch screen is then filtered, cleaned, and imported into SMART on a monthly basis. This ensures timely access to near real-time visitor data. The system also integrates various secondary data such as market data currently being used by the DMO and demographic data based on zip codes provided by other external agencies, etc. This information is then merged with the primary data to 


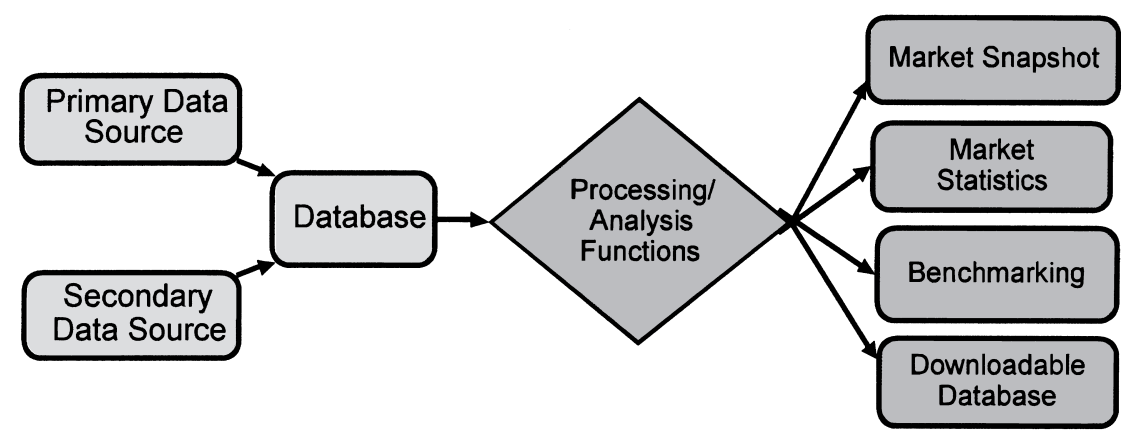

Figure 3. Conceptual framework of SMART-Baltimore.

provide a richer understanding and more accurate profiling of existing and potential markets and facilitate timely decision making.

The online system is designed as a passwordprotected system. It consists of four functional components which include "Market Snapshot," "Market Statistics," "Market Benchmarking," and "Downloadable Database." "Market Snapshot" provides instant access (the users do not have to specify search criteria) to the most important facts about visitor markets including "Market Segments," "Top 10 Markets," and "Monthly Visitors." "Market Statistics" enables users to perform a series of statistical analyses upon the visitor data. "Market Benchmarking," on the other hand, provides comparative analysis of various performance measures of the overall visitor market and individual market segments across different time periods. The "Downloadable Database" capability enables users to selectively generate downloadable data reports in Microsoft Excel format. SMART-Baltimore offers users a variety of approaches to access the database. For each of the four functional components, it enables users to easily query and segment the dataset. For example, the "Market Statistics" and "Downloadable Database" components provide two types of access methods: one for quick access and one with more sophisticated features. The "Market Statistics" component also enables users to specify their data layout preferences, view, and then download the sorted dataset in a customized way. In the "Market Snapshot" component, a set of data visualization tools has been created that can dynamically generate bar charts and provide the means to create visual presenta- tions of the respective data, thereby facilitating an easy interpretation of the data. In addition, SMARTBaltimore provides system-related documentation such as "What's New" and "Online Help" as well as industry information such as "Useful Links."

\section{Findings}

Interviews were conducted immediately after the initial evaluation process was completed and a decision was made to adopt SMART at BACVA. Based on these semistructured interviews with key informants at BACVA, it is clear that this is not a final irrevocable decision because evaluation, in reality, is an ongoing process. However, in practice this is a major decisio- making point after evaluation of the potential of the project and before further significant commitment of resources is made for development. The qualitative data collected during these interviews were summarized into six "themes" representing the key questions. These themes are consistent with the components of the proposed framework wherein the first two themes "BACVA's Rationale to Invest in SMART" and their perception of "ROI of SMART" represent the organizational variables of the construct. "SMART: An Effectiveness Project" corresponds to the role of the technology in the organization, followed by the two themes "SMART for BACVA Stakeholders," and "A Competitive Advantage and Risk for BACVA," which describe the interaction of this technology with the BACVA environment (both internal and external). The last theme, "A tool for Organizational Change," discusses the anticipated changes caused by these interactions. 
BACVA's Rationale to Invest in SMART-Baltimore

BACVA has been going through structural and leadership changes in the last 2 years. As the part of these changes BACVA has introduced an "Industry Barometer," which gauges the performance of the entire tourism industry in Baltimore, not just BACVA itself as an organization. They have introduced monthly productivity reports in all the departments. They have also just adopted a new organization wide system and database technology called "IDSS" to replace the current systems being used at the organization. In the words of the Research Manager, the most important reason for BACVA to invest in a market information system like SMART is:

SMART fits with the overall change that is going on with the entire shift in the organization. With the new management and new leadership accountability, is huge. It wasn't really focused on earlier from my understanding. Introduction of SMART is just one piece in the overall shift, in being more strategic and being accountable for work that we do...

\section{ROI of SMART-Baltimore}

BACVA is a technology-driven organization and the decision makers do not foresee that SMART is really an expense, because this system does not require recruiting any new staff members or specific technical equipment costs as this is an online technology and can be accessed by BACVA members from anywhere. However, they do realize some soft costs, especially in terms of the time spent in training the employees to use this system. There is a consensus that the return on investment is the richness of information and the timeliness of the real-time visitor data that are going to be provided through SMART. They admit that it is difficult to measure the performance of this system in the short run and that the real benefits will be realized only in the long run. From a marketing department standpoint, the VP of marketing indicated that:

we will continue to get the syndicated data from D. K. Shifflet [note: a major travel data provider in the United States] . . . so we won't reduce that. In the long term, it could certainly reduce costs because we are able to stop marketing programs that are not working. Since we know we are not reaching our target audience, we should be able to handle with the equipment we have. I would hire people who can deal with this technology. It is going to be an added parameter for hiring people.

From the research standpoint, "The return is information ... so it is hard to say what point it is fulfilled...this is something more on-going. Where we fulfill the investment I don't know ... cost of SMART is very affordable."

\section{SMART: An Effectiveness Project}

The decision makers perceive SMART-Baltimore to be a tool that will not only provide information to help satisfy their customer's needs but also serve as an analytical tool that will enable them to determine where they should allocate their resources. They appear to have identified this as an effectiveness project capable of reducing the costs of performing existing tasks as well as identifying different approaches of doing things. This will help them better achieve the required results, leading to increased revenues, and better service. For example, a comment was made by the Research Manager, "We want to make sure we are talking to today's visitors and not visitor from 4 years ago, hoping SMART will make us smarter." Echoing this comment, the VP of Marketing said,

We are going to be able to change tactics probably more frequently... maybe instead of stay with something when it is not working we will know faster if it is not working and switch off ... but it's all a matter of time ... data isn't good if you cannot use it...

The BACVA decision makers also perceive that this system will make their decision-making process more scientific rather than just based on instincts. Mining the information made available through this system will help them come up with innovative marketing ideas. The information provided through the system is a great asset to the CVB and will allow them to allocate their resources more strategically by eliminating nonvalue-added activities in the process. Also, this tool will enable them to change marketing tactics 
probably more frequently, especially in cases where the data suggest that a particular marketing strategy is not generating the required results. The VP of Marketing provided an example:

[The most important reason to invest in SMART] is the timeliness of data. ... A syndicated visitor volume study gives us similar data but with an 18 month lag. ... We got 2003 data mid 2004. ... It is like driving down the highway looking in the rear view mirror... . Market changes all the time. Being able to look at the data on a monthly basis will be incredibly helpful.... If we have current marketing data we can be more nimble in our marketing strategies.... If something might come up, or if there is a new feeder market, we could start marketing to them or we could see from our marketing efforts where people are coming from and where they aren't coming from ...

BACVA invests an enormous amount of advertising dollars in Washington, DC but does not receive the expected visitation from there. Currently, such failures are not obvious because the data provided by various databases are received only annually so decisions are based on older data instead of more recent visitations. Also, the COO suggested that in instances where there is a mismatch between the visitor's perception of destination image and the current marketing strategy, real-time data will enable the CVB to plan and reformulate strategies for such market segments. The COO opines that,

Data provides us a scientific way to know their [customer/visitors] needs and their perceptions about Baltimore... [the real time data from SMART could be used] to either develop products or understand the visitors perception about Baltimore. Maybe it is perceived by them that we don't have history or culture for African American, while in fact we do and that tells us that we need to do a better job with marketing...

\section{SMART for BACVA Stakeholders}

Members at BACVA understand that as a CVB they do not control the products they are marketing, but their role is to facilitate the experience of the tourist visiting the destination. The VP stated:

From a marketing perspective we are in an unusual position because we do not control the product. The product we market is the experience. It's our members who actually hold our brand and really what they look to us for is the kind of data that we are talking about right now. They are looking for industry trends which they, as small business owners, can't afford. That's why we focus on this kind of strategic research initiative....it's been so positive and so positively received by our members ...

SMART-Baltimore enables BACVA to control and have the right resources in place in order to get that data back to their members. Getting timely information through SMART-Baltimore would help them and the industry players react to the customer demands and proactively develop strategies that would enhance the visitor's experience. Members of BACVA perceive that such strategies would enable them to develop a positive reputation among the industry players, such as the governmental organizations, hotels, transportation suppliers, and local businesses, and creates a more positive image wherein BACVA is perceived as an organization that considers the end user to be a business partner and not just a consumer.

Like many other CVBs, BACVA is a quasigovernmental organization and receives significant percentage of revenues from fund allocation by the government or governmental agencies (e.g., part of their tax income). Because of this complex mix of revenues (from customers, members, and allocated funds), there is a great need to provide empirical evidence for the various financial decisions made by the organization. The $\mathrm{COO}$ of BACVA concluded:

The data provided by SMART will enable us to
provide empirical evidence for the various finan-
cial decisions made by the organization. This is
not only a cost saver but also a revenue generator
for the tourism industry of Baltimore area.

A Competitive Advantage and Risk for BACVA

Differences were noted in the informants' opinions on SMART's role to provide distinct values to the organizations competitive advantage. For instance, the $\mathrm{COO}$ indicated:

I think more the data, the better you are able to profile your customer. More distinct advantage you have over other bureaus or other marketing 
organizations that do not have the data. In this aspect it does give us a distinctive scientific advantage.

The VP of Marketing further indicated that:

It is hard to compare our research needs with our competitors. SMART will make us be more strategic and focused. I don't know about the competitive advantage but it will make us a better marketing organization.

However, the Research Manager stated,

It's at the forefront. ... We are in the first pack ... I would not say it's unique ... we need to do this now or else.... If you are not doing it or starting to do it; you are going to fall behind ...

Importantly, all the key informants indicate that they do not see any organizational risk in integrating this system with the company strategy (i.e., it is possible to handle the system with existing management and technical teams).

\section{A Tool for Organizational Change}

Finally, the BACVA management was asked the following questions: Do you see any effects of this system on different levels of management and cross functional areas? And do you think this system will help improve management control and assist the management to control the performance? In response, the VP of marketing suggested that,

I think we are going to be able to better control our marketing efforts which would lead to performance. It's kind of a leap but its going to affect us, more from a market and marketing research standpoint than functionally across the organization. Most important, it will make my department even more research driven.

When asked how do they think introducing this system will affect the attitude of the members of the organization towards the use of technology, the informants suggested that the introduction of an analytical tool like SMART-Baltimore to the pool of existing technologies would: 1) assist their visitor center staff members perform their jobs more efficiently and effectively; 2) make them feel more valuable to the organization; 3) make them more accountable towards the organization; and, 4) facilitate better communication at various levels of the organization through easily accessible information.

\section{Implications for Destination Marketing}

The critical challenge for CVBs is to effectively integrate technology and adjust organizational approaches so that these new developments in the market and industry environment can be successfully addressed. Hence, finding and processing the correct data to support their marketing strategies is one of the principal problems of tourism managers. The present article introduced SMART-Baltimore as an IT structure that combines powerful databases supported by innovative decision support systems. Thus, information generated using SMART-Baltimore will enable the bureau to not only personalize services but also customize them to match consumer needs with organizational capabilities and offerings, enabling them to meet customer needs as profitably as possible.

Studies relating to CVBs have suggested that they are slow in adopting new technologies (Yuan et al., 2006), website innovation (Zach, Xiang, \& Fesenmaier, 2006), and adopting decision support systems (Wöber \& Gretzel, 2000). Similarly, the experience from the discussions during this study suggests that the leadership at BACVA understands the potential of destination marketing information systems as a tool to improve their marketing efforts; however, it appears that they do not recognize the potential of this system to cause an overall change in the organization. Based on the results of the study, it can be concluded that BACVA is at the "Substitution" stage. BACVA seems to have structures that support innovation and adoption of new technology; however, there is a greater need for organizational transformation, which is an important characteristic of the Reconfiguration stage. An organizational culture that is strategy focused and driven by balanced performance measures will enable bureaus to adapt more readily to the rapidly changing environment (Kothari, Xiang, \& Fesenmaier, 2006). Adopting SMART-Baltimore at the organization wherein bureau staff engage themselves in proactively 
learning from their own experience and best practices of the industry will facilitate change in the way of thinking that enables bureaus to transform themselves into "learning organizations" where learning and measurement are the foundations for development of the system and finally, for the growth of the organization.

Although the exact impact of this system are far from clear, the future of this new system will be more focused on consumer centric tools that will enable the bureau to focus on their destination marketing goals through a network of partnerships. The aim of this system is to provide an improved evaluation of future market developments and eventually to integrate the findings into the strategic planning process of national and regional tourism organizations and businesses. Considering that there is a strong relationship between bureaus learning and growth efforts to the overall economic impact on the destination, the success of SMART-Baltimore needs to be evaluated through the success of the destination, spread of tourism flows to the regions, timeliness, and accuracy of information to the industry operators, enhancement of tourist yield, and the ability of the system to facilitate the decision-making process for its users. In order to understand this, as a part of the postimplementation review process, in-depth interviews will be conducted at regular time intervals with various levels of users and decision makers at the organization and at the partner organizations in order to better understand the impact of SMART-Baltimore on the bureau and the destination over a longitudinal period of time. Conducting an evaluation such as this study at various intervals will enable not only the members of BACVA but also members of the tourism industry to understand impacts of implementing a marketing information system into their organizations.

\section{Biographical Notes}

Tanvi Kothari is a doctoral student at the General and Strategic Management department at the Fox School of Business and Management, Temple University. She received her master's degree from the School of Tourism and Hospitality Management and has served as a research assistant at the National Laboratory for Tourism \& eCommerce. Her main research and teaching interests focus on strategic management issues relating to tourism organizations.
Zheng Xiang is an assistant professor in the School of Merchandising and Hospitality Management, University of North Texas. His research interests include travel information search on the Internet, Internet marketing strategies, and travelers' online behavior.

Daniel R. Fesenmaier is Professor and Director of the National Laboratory for Tourism \& eCommerce, School of Tourism and Hospitality Management, Temple University. His research and teaching interests include information search, travel decisions and the Internet as well as the development of marketing information systems for the tourism industry.

\section{References}

Banker, R. D., Kauffman, R. J., \& Morey, R. C. (1990). Measuring gains in operational efficiency from information technology: A study of the positran deployment at Hardee's Inc. Journal of Management Information Systems, 7(2), 29-54.

Barua, A., Kriebel, C. H., \& Mukhopadhyay, T. (1991). An economic analysis of strategic information technology investments. MIS Quarterly, 15(3), 313-331.

Bateman, T. S., \& Zeithaml, C. P. (1993). Management: Function and strategy. Boston: McGraw-Hill/Irwin.

Bhatt, G. D., \& Zaveri, J. (2002). The enabling role of decision support systems in organizational learning. Decision Support Systems, 32, 297-309.

Brynjolfsson, E. (1993). The productivity paradox of information technology. Communications of the ACM, 36(12), 67-77.

Buhalis, D. (1998). Stategic issues of information technologies in the tourism industry. Tourism Management, 19(5), 409-421.

Contractor, N. S., Stohl, C., Monge, P., Flanagin, A., \& Fulk, J. (2000). Communication in the global workplace: Advanced e-quad collaboration tools to support multi-university cooperative learning and teaching. Working paper, University of Illinois.

Contractor, N. S., Wasserman, S., \& Faust, K. (1999). Testing multi-level, multi-theoretical hypotheses about networks in 21st century organizational forms: An analytic framework and empirical example. Retrieved June 1, 2005, from http://www.spcomm.uiuc.edu/users/nosh/ manuscripts/pstarpaper.html

Daft, R. L., \& Lengel, R. H. (1986). Organizational information requirements, media richness and structural design. Management Science, 32(5), 554-571.

Davenport, T. H., \& Short, J. E. (1990). The new industrial engineering: Information technology and business process reengineering. Sloan Management Review, 31(4), $11-28$.

DePietro, R., Wiarda, E., \& Fleischer, M. (1990). The context for change: Organization, technology and environment. In L. G. Tornatzky \& M. Fleischer (Eds.), The processes of technological innovation (pp. 151-175). Lexington, MA: Lexington Books. 
DeSanctis, G., \& Poole, M. S. (1994). Capturing the complexity in advanced technology use: Adaptive structuration theory. Organization Science, 5(2), 121-147.

Dewey, J. (1929). Experience and nature. New York: Dover.

Dill, W. R. (1962). The impact of environment on organizational development. In S. Malick \& E. H. VanNess (Eds.), Concepts and issues in administrative behavior (pp. 29-43). Englewood Cliffs, NJ: Prentice-Hall.

Dohertya, N. F., Kinga, M., \& Al-Mushayt, O. ( 2003). The impact of inadequacies in the treatment of organizational issues on information systems development projects. Information \& Management, 41, 49-62.

Drucker, P. F. (1985). Playing in the information-based 'orchestra.' Wall Street Journal.

Duncan, R. B. (1972). Characteristics of organizational environment and perceived environment uncertainty. $A d$ ministrative Science Quarterly, 17(3), 313-327.

Elliott, J. (1997). Tourism: Politics and public sector management. London: Routledge.

Farbey, B., Land, F., \& Target, D. (1999). Moving is evaluation forward: Learning themes and research issues. Journal of Strategic Information Systems, 8(2), 198207.

Fesenmaier, D. R., Gretzel, U., Hwang, Y. H., \& Wang, R. (2004). Applications of Internet technology in travel and tourism. . In H. Bidgoli (Ed.), The Internet encyclopedia (Vol. 3, pp. 459-476). Bakersfield, CA: John Wiley \& Sons.

Fesenmaier, D. R., Leppers, A. W., \& O'Leary, J. T. (1999). Developing a knowledge-based tourism marketing information system. Information Technology \& Tourism, 2, 31-44.

Fitzgerald, G. (1998). Evaluating information systems projects: A. Multidimensional approach. Journal of Information Technology, 13(15-28).

Gates, B. (1999). Business at the speed of thought. New York: Warner Books Inc.

Goodhue, D. L. (1995). Understanding user evaluations of information systems. Management Science, 41(12), 18271844.

Gretzel , U., \& Fesenmaier, D. R. (2001). Defining internet readiness for the tourism industry: Concepts and case study. In H. Werthner \& M. Bichler (Eds.), Lectures in e-commerce. Wien: Springer Verlag.

Gretzel, U., \& Fesenmaier, D. R. (2004). Implementing a knowledge-based tourism marketing information system: The Illinois tourism network. Information Technology \& Tourism, 6, 245-255.

Hill, T. (1993). Manufacturing strategy: The strategic management of the manufacturing function (2nd ed.). London: Macmillan.

Kanter, R. M. (2001). Evolve: Succeeding in the digital culture of tomorrow. Boston: Harvard Business School Press.

Kauffman, R. J., \& Weill, P. (1988). An evaluative framework for research on the performance effects of information technology investment. In P. Berger, J. G. Ko- bielus, \& D. E. Sutherland (Eds.), Measuring the business value of it. Washington, DC: ICIT Press.

Kothari, T., Xiang, Z., \& Fesenmaier, D. R. (2006). Performance measurement at destination marketing organizations. Paper presented at the 11th Annual Graduate Education and Graduate Student Research Conference in Hospitality and Tourism, Seattle, WA.

Kvale, S. (1996). Interviews: An introduction to qualitative research interviewing. London: Sage Publications.

Little, J. D. C. (1970). Models and managers: The concept of a decision calculus. Management Science, 16(8), $466-485$.

Mazanec, J. A. (1986). A decision support system for optimizing advertising policy of a national tourist office: Model outline and case study. International Journal of Research in Marketing, 3, 63-77.

Mikkelsen, B. (1995). Methods for development work and research: A guide for practitioners. London: Sage Publications.

Miles, M. B., \& Huberman, A. M. (1994). Qualitative data analysis. Thousand Oaks, CA: Sage Publications.

Murphy, P. E. (1985). Tourism: A community approach. New York: Methuen.

Mutch, A. (1996). The English tourist network automation project: A case study in interorganizational system failure. Tourism Management, 17(8), 603-609.

Orlikowski, W. (1992). The duality of technology: Rethinking the concept of technology in organizations. $\mathrm{Or}$ ganization Science, 3(3), 398-427.

Palmer, A. J. (1996). Relationship marketing: A universal paradigm or management fad? The Learning Organization, 3(3), 18-25.

Patton, M. Q. (1990). Qualitative evaluation and research methods (2nd ed.). Newbury Park, CA: Sage Publications.

Poon, A. (1993). Tourism, technology and competitive strategies. Wallingford: $\mathrm{CAB}$ International.

Porter, M. E. (1985). Competitive advantage: Creating and sustaining superior performance. New York: The Free Press.

Remenyi, D., Sherwood-Smith, M., \& White, T. (1998). Achieving maximum value from it investments. Chichester: John Wiley \& Sons.

Ritchie, R. J. B., \& Ritchie, J. R. B. (2002). A framework for an industry supported destination marketing information system. Tourism Management, 23(5), 439-454.

Rogers, E. M. (1983). Diffusion of innovations (3rd ed.). New York: The Free Press.

Schertler, W. (1994). Impact of new information technologies on tourism industry and business. The Tourist Review, 2, 2-8.

Scott, W. G. (1961). Organization theory: An overview and an appraisal. Academy of Management Journal, 4, 7-26.

Seth, J. N., \& Parvatiyar, A. (1995). The evolution of relationship marketing. International Business Review, 44(4), 397-418.

Sriram, V., Stump, R. L., \& Banerjee, S. (1997). Information technology investments in purchasing: An empiri- 
cal study of dimensions and antecedents. Information \& Management, 33, 59-72.

Sutton, H. (1988). Competitive intelligence. New York: The Conference Board.

Templer, A. (1989). Human resource managers and the new technology agenda. Journal of General Management, 15(2), 73-80.

Terreberry, S. (1968). The evolution of organizational environments. Administrative Science Quarterly, 12, 590613.

Thorp, J. (1996). The information paradox: Realizing the business benefits of information technology. Toronto: McGraw-Hill Ryerson.

Tornatzky, L. G., \& Fleischer, M. (1990). The processes of technological innovation. Lexington, MA: Lexington Books.

Tushman, M., \& Scanlan, T. (1981). Boundary spanning individuals: Their role in information transfer and their antecedents. Academy of Management Journal 24(2), 289-305.

Van de Ven, A. H., \& Drazin, R. (1985). The concept of fit in contingency theory. Greenwich, CT: JAI Press.

Venkatraman, N. (1989). Strategic orientation of business enterprise: The construct, dimensionality, and measurement. Management Science, 35(8), 942-962.

Venkatraman, N., \& Ramanujam, V. (1987). Measurement of business economic performance: An examination of method convergence. Journal of Management, 13(1), 109-122.

Werthner, H., \& Klein, S. (1999). Information technology and tourism: A challenging relationship. New York: Springer.

Willcocks, L., \& Lester, S. (1994). Evaluating the feasibility of information systems investments: Recent uk evidence and new approaches. In L. Willcocks (Ed.), Information management: The evaluation of information systems (pp. 49-77). UK: Chapman \& Hall.
Willcocks, L., \& Lester, S. (1997). In search of information technology productivity: Assessment issues. Journal of the Operational Research Society, 48(11), 1082-1094.

Wilson, D. (1993). Assessing the impact of information technology on organizational performance. In R. D. Banker, R. J. Kauffman, \& M. A. Mahmood (Eds.), Strategic information technology management: Perspectives on organizational growth and competitive advantage. Harrisburg, PA: Idea Group Publishing.

Wöber , K. W. (2003). Information supply in tourism management by marketing decision support systems. Tourism Management, 24, 241-255.

Wöber, K., \& Gretzel, U. (2000). Tourism manager's adoption of marketing decision support systems. Journal of Travel Research, 39(2), 172-181.

Yin, R. K. (1984). Case study research: Design and method. Beverly Hills, CA: Sage Publications.

Yin, R. K. (2002). Case study research: Design and methods (3rd ed.). Thousand Oaks, CA: Sage Publications Inc.

Yuan , Y., \& Fesenmaier, D. R. (2000). Preparing for the new tourism economy: The use of the Internet and intranet in American convention and visitor bureaus. Information Technology \& Tourism, 3(2), 71-85.

Yuan, Y., Gretzel, U., \& Fesenmaier, D. R. (2003). Internet technology use by American convention and visitors bureaus. Journal of Travel Research, 41(3), 240-255.

Yuan, Y., Gretzel, U., \& Fesenmaier, D. R. (2006). The role of information technology use in American convention and visitors bureaus. Tourism Management, 27(2), 326-341.

Zach, F., Xiang, Z., \& Fesenmaier, D. R. (2006, June 1821). Innovation in Internet marketing by American CVBs. Paper presented at the Annual Meeting of Travel and Tourism Research Association, Dublin, Ireland. 